\title{
Investigating Local Climate Zones for Outdoor Thermal Comfort Assessment in an Indian City
}

\author{
Rajashree Kotharkar ${ }^{A^{*}}$, Anurag Bagade ${ }^{\mathrm{A}}$, Abhay Agrawal ${ }^{\mathrm{A}}$ \\ Received: November 30, 2019 | Revised: December 26, 2019 | Accepted: December 26, 2019 \\ DOI: $10.5937 / g p 23-24251$
}

\begin{abstract}
The rapid growth of development and urbanization in the Indian subcontinents has made the urban areas vulnerable to outdoor thermal discomfort (OTC) which is in turn affecting the quality of living in these areas. This study aims at evaluating spatiotemporal dynamics of outdoor thermal comfort in Nagpur city (India) during winter, summer and heat wave period using Local Climate Zone (LCZ) classification. It uses Thom's Discomfort Index (DI) and Relative Strain Index (RSI) to analyze outdoor thermal comfort. It also examines the significance of major LCZs in addressing thermal anomaly and OTC at different time periods using One-way ANOVA technique. It identifies critical LCZ having a maximum exposure of discomfort and concludes with the applicability of LCZ for addressing discomfort.
\end{abstract}

Keywords: Heat Island; Heatwave; Local Climate Zone; Relative Strain Index; Discomfort Index

\section{Introduction}

Rapid development and urbanization have changed various physical factors such as built to open space ratio, use of impervious construction materials, affecting the microclimate in urban areas (Rose et al., 2011). Various climatic, geographic, built and anthropogenic factors further contribute to the development of positive temperature anomaly in urban areas (Oke, 1982). Exposure to extreme heat presents a health hazard (Arsenović et al., 2019) to all but particularly to outdoor workers in low and middle-income tropical countries as they are involved in heavy physical work with minimal access to cooling systems while working (Hanna et al., 2011). Study of thermal comfort becomes necessary for such regions. However, due to diverse landscape, socio-economic conditions and climate variations pose a difficulty in assessing thermal comfort for an entire city. Comfort studies focusing on a specific urban fabric in such regions may not be replicable over other regions of the same city. Furthermore, culminating outdoor comfort assessment research into a citywide planning proposal presents practical difficulties. Use of appropriate scale emerges as an important factor when existing studies demand comparative evaluation before transforming into policies or guidelines for city-level planning (Bajšanski et al. 2015, Milošević et al. 2017). A small scale study presents advantages in terms of resource management as an experimental setup and data collection becomes convenient. As the scale gets bigger, it becomes difficult to gather and assess information on all the parameters affecting comfort. This leads to the need for standardization for outdoor thermal comfort studies (Johansson et al., 2014). Merely accounting climatic variables through a top to bottom approach at a national or regional level diminishes local mitigation opportunities.

Local Climatic Zones (LCZs) are climate based classification of the city fabric (Bechtel et al., 2015; Stewart \& Oke, 2012). It is defined as "regions of uniform surface cover, structure, material, and human activity that span from hundreds of meters to several kilometers in horizontal scale" (Stewart \& Oke, 2012). Various re-

\footnotetext{
A Visvesvaraya National Institute of Technology, Department of Achitecture and Planning, Nagpur, India

* Corresponding author: e-mail: rskotharkar@gmail.com
} 
searchers are further exploring the applicability of LCZ concept for understanding the bio-meteorological aspects of urban planning and design. Wu et al. (2016) associated vegetation with outdoor thermal comfort in a residential area of Beijing (China) using LCZ as a medium of spatial evaluation. Unger et al (2018) comparative study of LCZs using physiologically equivalent temperature (PET) comfort index and justified the urban area's subdivision using LCZ classification for comfort studies. Verdonck et al (2018) identified potential hotspots using LCZs and analyzed heat stress over three cities in Belgium. Villadiego and Velay-Dabat (2014) studied ASHRAE mean thermal sensation votes and LCZ for in Barranquilla for understanding thermal sensation in tropics. Geletič et al (2018) studied outdoor thermal conditions amongst various LCZs using HUMIDEX index. Müller et al. (2013) compared LCZs within inner city regions of Oberhausen (Ger- many) using PET. Milošević et al. (2016) accessed outdoor human thermal comfort in local climate zones of Novi Sad (Serbia) during heat wave period. These studies support the significance of LCZ in evaluating outdoor thermal comfort. However, major studies on LCZ and thermal comfort are carried in planned cities of developed countries. Cities of developing countries, especially those located in the tropics, have a heterogeneous built form (Kotharkar \& Bagade, 2018).

This study explores LCZ, a proven classification system for understanding and evaluating the thermal environment of urban and rural studies, as a potential guideline for assessing outdoor thermal comfort in tropics. The paper aims at studying outdoor thermal comfort along with temperature anomaly among built LCZs in a tropical city (Nagpur) during winter, summer and heat wave period at different time period of interest.

\section{Study area, data and methods}

The study is conducted in four phases as illustrated in Figure 1. The first phase includes the selection of a case study. It examines the city's local climate zones and their spatial arrangement. It identifies the major built LCZs, having higher coverage area, present in the city for comfort assessment. The second stage includes the station survey and collection of meteorological data from major LCZs. Third stage deals with the selection of thermal comfort index through literature review, selection of time period for investigation based on human activity pattern and, evaluation of thermal anomaly and comfort parameters. Final stage examines the significance of thermal anomaly and outdoor thermal comfort index in different LCZs. It concludes with the identification of comfort critical LCZs in the city.

Study areaNagpur city is located between $78^{\circ} 30^{\prime}$ to $79^{\circ} 30^{\prime} \mathrm{E}$ longitudes and $20^{\circ} 30^{\prime}$ to $21^{\circ} 45^{\prime} \mathrm{N}$ latitudes in the state of Maharashtra, India (CRISIL Risk and Infrastructure Solutions Limited, Ministry of Urban development 2015) (see Figure 2). With a geographical area of $225.08 \mathrm{~km}^{2}$, the city has an average population of 2.5 million. In peripheral areas, density is as low as 2032 person per hectare ( $\mathrm{pph}$ ) whereas inner and core area's density is as high as 750-1000 pph (Kotharkar, Bahadure, and Sarda 2014). It features a tropical wet

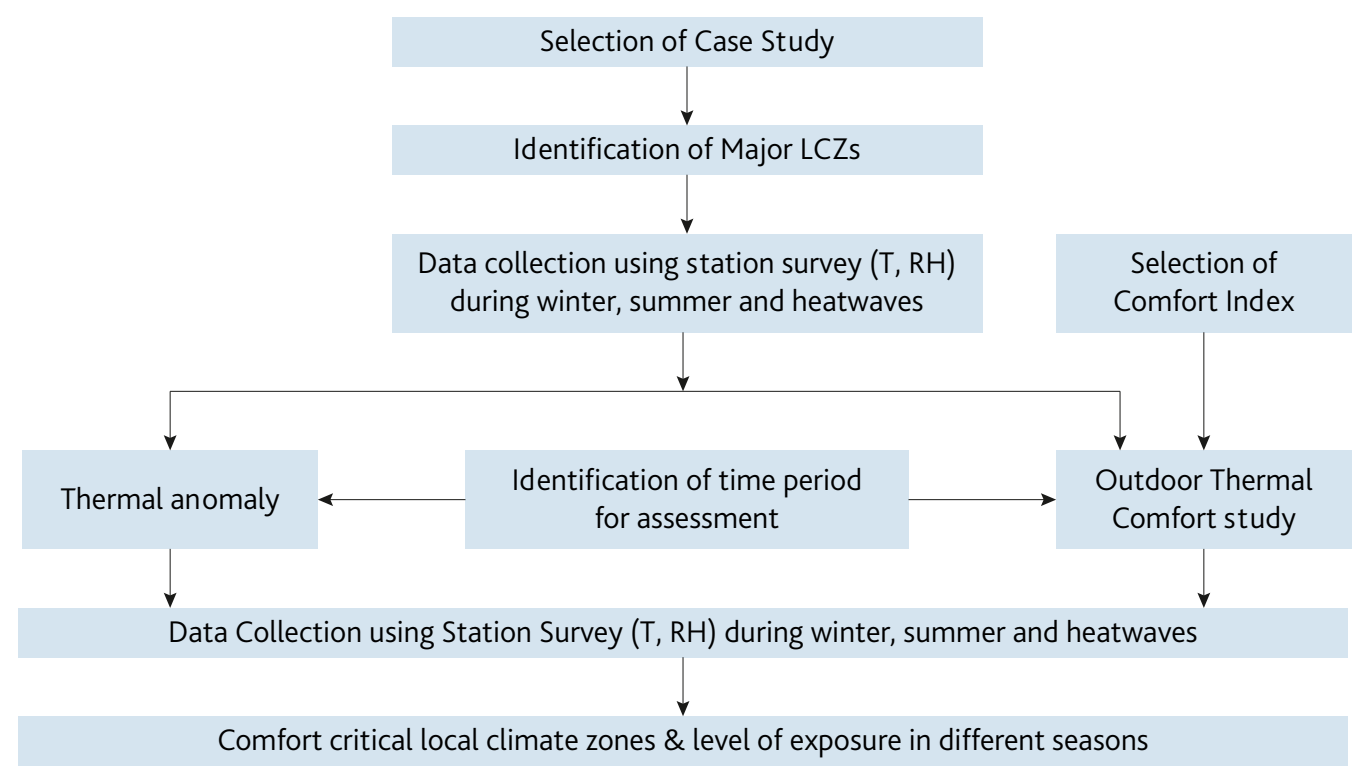

Figure 1. Research design for spatio-temporal analysis of outdoor thermal comfort 
and dry climate. Annual temperature varies from a minimum of $4^{\circ} \mathrm{C}$ in winter (December to February) to a maximum of $48^{\circ} \mathrm{C}$ in summer season (March to May) (CRISIL Risk and Infrastructure Solutions Limited, Ministry of Urban development 2015). Summers also experience heat wave when the temperature rises drastically over the entire city. In 2016, Nagpur observed frequent heatwaves during the period of 18 to 27 May. As per National Disaster Management Authority (NDMA), Government of India, a heat wave is a period when temperatures are abnormally high than normal maximum temperatures, occurring during the summer months ("National Heat Wave", 2018). As per the Indian Meteorological Department (IMD), heat wave condition is to be declared once the temperature crosses $45^{\circ} \mathrm{C}$. In hills and plains, heat waves are not considered unless the temperature reaches at least $30^{\circ} \mathrm{C}$ and $40^{\circ} \mathrm{C}$ respectively (National Disaster Management Authority, 2016).

\section{LCZ setting}

Nagpur's city form is heterogeneous and includes varying roughness feature, built material and land-use pattern. Kotharkar \& Bagade (2018) prepared LCZ classification map of Nagpur through filtering data from various sources and applying manual method of overlay and deduction technique at a resolution of 500 meters (refer Figure 2g). Nagpur city has all the standard LCZs except LCZ 1, 2 and LCZ 10. LCZ subclasses are found to be inherent features of the city. Out of the twenty-three LCZs spread within the city; natural type of LCZs comprises $33.85 \%$ while built type covers $66.15 \%$ of the total municipal area. Nagpur's city limit is surrounded by sparse type of development which extends into LCZ F and other natural LCZs. Major LCZs constituting $80 \%$ of the city's built landcover include $\mathrm{LCZ}_{3}, \mathrm{LCZ}_{3_{\mathrm{F}}}, \mathrm{LCZ} 6, \mathrm{LCZ} 6_{5}, \mathrm{LCZ} 6_{\mathrm{B}}$ and LCZ 9. These LCZs were selected for the study (Table 1 ).

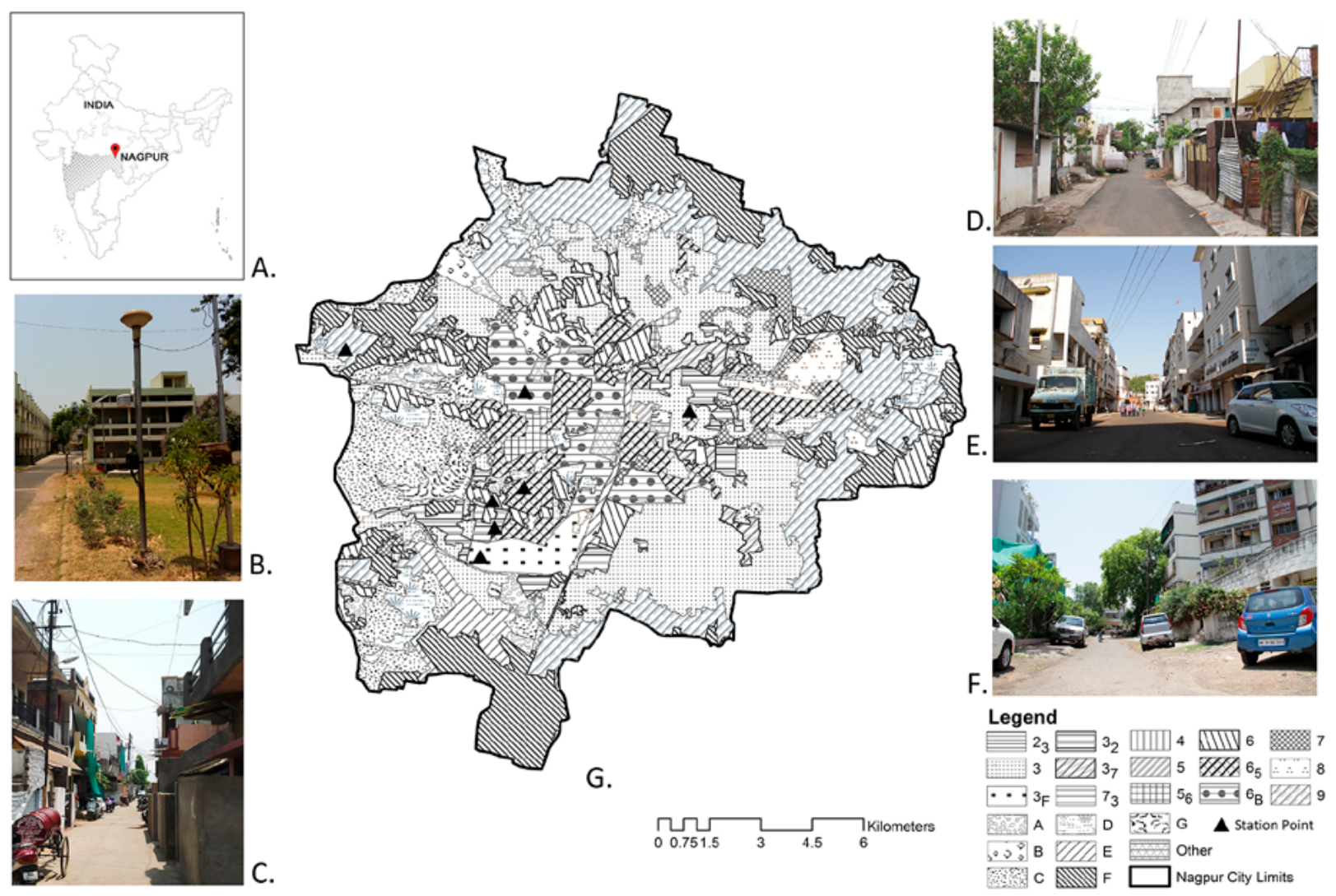

Figure 2. Map of Nagpur city showing a. Location of City; b. Placing of Station Point in LCZ 6; Canopy level photographs of c. LCZ 3, d. LCZ 9, e. LCZ 3, f. LCZ $6{ }_{5}$ and, g. Local climate zone classification (modified from Kotharkar \& Bagade, 2017) with location of monitoring stations 
Table 1. LCZ description, properties used in mapping and coverage in Nagpur city

\begin{tabular}{|l|l|c|c|c|c|c|c|c|c|}
\hline \multicolumn{2}{|l|}{ LCZ Details } & \multicolumn{2}{l|}{ LCZ properties } & \multicolumn{2}{l|}{ Coverage } \\
\hline LCZ & Description & AR & BSF & $\begin{array}{c}\text { Imper- } \\
\text { vious } \\
\text { ratio 'I' }\end{array}$ & $\begin{array}{c}\text { Pervious } \\
\text { ratio 'P' }\end{array}$ & $\begin{array}{c}\text { Vegeta- } \\
\text { tion 'V' } \\
\text { in \% }\end{array}$ & $\begin{array}{c}\text { Height of } \\
\text { Rough- } \\
\text { ness 'H' }\end{array}$ & $\begin{array}{c}\text { Terrain } \\
\text { Rough- } \\
\text { ness 'T' }\end{array}$ & $\begin{array}{c}\text { Area (LCZ } \\
\% \text { within } \\
\text { built) }\end{array}$ \\
\hline LCZ 3 & Compact low-rise & $0.75-2$ & $40-80$ & $20-50$ & $<30$ & $<25$ & $3-10$ & 6 & 30.81 \\
\hline LCZ 6 & Open low-rise & $0.3-0.75$ & $20-40$ & $20-40$ & $30-70$ & $30-60$ & $3-10$ & $5-6$ & 8.62 \\
\hline LCZ 9 & Sparsely built & $0.1-0.25$ & $10-20$ & $<20$ & $60-80$ & $<20$ & $3-10$ & $5-6$ & 24.94 \\
\hline LCZ 3 F & $\begin{array}{l}\text { Compact low-rise } \\
\text { nesting soil }\end{array}$ & $0.75-1.5$ & $30-60$ & $20-40$ & $<40$ & $<40$ & $3-10$ & $5-6$ & 2.64 \\
\hline LCZ 6 5 & $\begin{array}{l}\text { Open low-rise nesting } \\
\text { open midrise }\end{array}$ & $0.3-0.75$ & $30-50$ & $10-40$ & $20-60$ & $20-50$ & $3-25$ & $5-6$ & 9.16 \\
\hline LCZ 6 & $\begin{array}{l}\text { Open low-rise nesting } \\
\text { scattered trees }\end{array}$ & $0.3-0.75$ & $20-40$ & $10-30$ & $40-70$ & $40-70$ & $3-10$ & $5-6$ & 6.64 \\
\hline LCZ 3 2 & $\begin{array}{l}\text { Compact low-rise nest- } \\
\text { ing compact mid-rise }\end{array}$ & $0.75-2$ & $40-70$ & $30-50$ & $<30$ & $<20$ & $3-18$ & $6-7$ & 4.69 \\
\hline
\end{tabular}

$A R$ is aspect ratio calculated as building height to adjacent road width ratio.

BSF is building surface ratio calculated as the ratio of impervious to pervious surface percentage

\section{Measuring thermal comfort}

Various scales and indices have been developed for thermal comfort and heat stress which gives numerical relations or graphs for evaluating thermal comfort (Abdel-Ghany et al., 2013). Literature-based on cities, their climate type, indices used and comfort reporting was studied for selecting appropriate thermal comfort index. Each index has their own strength in terms of comprehensiveness, usability, validity and completeness (Freitas \& Grigorieva, 2017). PET was observed as a widely used outdoor thermal comfort index in tropics. Other indices such as Thom's Discomfort Index (DI) (Nieuwolt, 1977) and Relative Strain Index (RSI) are commonly used in urban climate studies (Kyle, 1992; Unger, 1999). DI is used to describe thermal sensations experienced by people as a result of modifications in the climatic conditions of the urban areas (Polydoros and Cartalis 2014; Stathopoulou et al. 2005). It is a more suitable index for the tropics (Emmanuel, 2005). RSI allows the effect of clothing and net radiation to be considered along with the effects of temperature and humidity. The RSI for a healthy 25 year-old male, unacclimatized to heat and in a business clothing; with an internal heat production of $100 \mathrm{~W} / \mathrm{m}^{2}$ and in the absence of direct solar radiation and a wind speed of $1 \mathrm{~m} / \mathrm{s}$ is given RSI formula (Unger, 1999).

Both indices, RSI and DI, use temperature and relative humidity $(\mathrm{RH})$ meteorological parameters only to deduce the thermal comfort. Unlike PET and UTCI, other factors such as variation in solar radiation, wind velocity, and clothing condition are not taken into account in these indices. At city level, local comfort assessment requires a large number of monitoring stations which account these parameters. Many studies often focus over temperature and $\mathrm{RH}$ data and ex- trapolate other parameters using Weather Research and Forecasting model (WRF) (Bajšanski et al., 2015) or obstacle-resolving numerical models (Fischereit \& Schlünzen, 2018). In a heterogeneous built city like Nagpur, extrapolation of indices may lead to misinterpretation of results.

The present study uses DI and RSI to study outdoor thermal comfort in LCZs. These indices were selected on the basis of cost-effectiveness in the experimental setup, ease to access of data, and spatial coverage. Temperature anomaly (TA), an indicator to UHI, presents a better visualization of LCZ's hourly thermal progressions. It is used to understand the thermal variations in LCZs throughout the day (Lemonsu et al., 2015).

HOBO U-23 Pro V2 temperature and RH (RH) sensor was placed inside a radiation shield and positioned in the representative LCZ at a height of $1.5 \mathrm{~m}-2 \mathrm{~m}$ from the ground. The temperature sensor has an accuracy of $\pm 0.21^{\circ} \mathrm{C}$ from $0^{\circ}$ to $50^{\circ} \mathrm{C}$ and resolution of $0.02^{\circ} \mathrm{C}$ at $25^{\circ} \mathrm{C}$ whereas humidity sensor has an accuracy of $\pm 2.5 \%$ from $10 \%$ to $90 \%$ RH (typical) to a maximum of $\pm 3.5 \%$. Temperature and $\mathrm{RH}$ data were collected at an interval of five minutes during winter $(28$ January to 6 February 2016), summer ( 5 to 14 May 2016) and heat wave period (18 to 27 May 2016).

TA, DI, and RSI were calculated based on standard equations (refer Table $2 \&$ Table 3 ). One way ANOVA test (Welch's method) was used to identify whether LCZs' are significantly different in mean thermal anomaly and mean outdoor thermal comfort indices at different periods in a day. These periods were selected on the basis of inhabitant's outdoor activity patternworking hours (Morning 9 am to evening $6 \mathrm{pm}$ ), the transition period from office, market and home (evening $6 \mathrm{pm}$ to $10 \mathrm{pm}$ ) and nocturnal hours (10 pm to $6 \mathrm{am}$ ). 
Table 2. Measuring Thermal Anomaly and Thermal Discomfort Indices

\begin{tabular}{|c|c|c|}
\hline Index & Formulae and Procedure & Variables used \\
\hline TA & $T A t=\bar{T}_{L C Z}-\bar{T}$ & $\begin{array}{l}\equiv \text { Mean temperature of all } L C Z \text { at time ' } t \text { ' } \\
\equiv \text { Mean temperature of individual } L C Z \text { at time ' } t \text { ' }\end{array}$ \\
\hline DI & $D I=T-(0.55-0.0055 T H) \cdot(T-14.5)$ & $\begin{array}{l}\mathrm{T} \equiv \text { Air Temperature }\left({ }^{\circ} \mathrm{C}\right) \\
\mathrm{RH} \equiv \text { Relative humidity }(\%)\end{array}$ \\
\hline \multirow[t]{4}{*}{ RSI } & $R S I=\frac{t-21}{58-e}$ & $\begin{array}{l}\mathrm{t} \equiv \text { air temperature }\left({ }^{\circ} \mathrm{C}\right) \\
\mathrm{e} \equiv \text { vapor pressure }(\mathrm{hpa})\end{array}$ \\
\hline & $\begin{array}{l}\text { Step I - Derive } T_{w} \\
R H=100-\frac{300\left(T_{a}-T_{w}\right)}{T_{a}} \\
\text { Source: (Neuberger \& Cahir, 1969) }\end{array}$ & $\begin{array}{l}\mathrm{T}_{\mathrm{a}} \equiv \text { dry bulb temperature }\left({ }^{\circ} \mathrm{F}\right) \\
\mathrm{T}_{\mathrm{w}} \equiv \text { wet bulb temperature }\left({ }^{\circ} \mathrm{F}\right)\end{array}$ \\
\hline & $\begin{array}{l}\text { Step II - Calculate } \mathrm{e}_{\mathrm{s}} \\
e_{s}=6.112 \exp \frac{17.68 \cdot T_{w}}{T_{w}+243.5} \\
\text { Source: (Souch \& Souch, } 1993 \text { ) }\end{array}$ & $\begin{array}{l}\mathrm{T}_{\mathrm{w}} \equiv \text { wet bulb temperature }\left({ }^{\circ} \mathrm{C}\right) \\
\mathrm{e}_{\mathrm{s}} \equiv \text { saturated vapor pressure }(\mathrm{hpa})\end{array}$ \\
\hline & $\begin{array}{l}\text { Step III - Calculate e } \\
R H=\frac{e}{e_{s}} \cdot 100\end{array}$ & $\begin{array}{l}\mathrm{e} \equiv \text { actual vapor pressure (hpa) } \\
\mathrm{RH} \equiv \text { relative humidity }\end{array}$ \\
\hline
\end{tabular}

Table 3. Discomfort Conditions for DI and RSI

\begin{tabular}{|c|c|l|l|l|}
\hline Zone & DI & CONDITION & RSI & CONDITION \\
\hline I & $<21$ & No Discomfort & 0.1 & $100 \%$ unstressed (everyone comfortable) \\
\hline II & $21 \leq \mathrm{DI}<24$ & Below 50\% population feels discomfort & 0.2 & $75 \%$ unstressed \\
\hline III & $24 \leq \mathrm{DI}<27$ & More than 50\% population feels discomfort & 0.3 & $0 \%$ unstressed (upper limit of comfort) \\
\hline IV & $27 \leq \mathrm{DI}<29$ & Almost everyone experience discomfort & 0.4 & $75 \%$ distressed \\
\hline $\mathrm{V}$ & $29 \leq \mathrm{DI}<32$ & Everyone feels heat stress & 0.5 & $100 \%$ distressed \\
\hline $\mathrm{VI}$ & $\mathrm{DI} \geq 32$ & Medical Emergency & & \\
\hline
\end{tabular}

Source: Thom, 1959; Unger, 1999

\section{Results}

\section{Air temperature and $\mathrm{RH}$ trends}

LCZs' temperature and $\mathrm{RH}$ parameters were plotted for different seasons and their maxima-minima trend was observed (Figure 3 and Figure 4). In winter, the temperature of LCZs within the city ranges from 8.52 ${ }^{\circ} \mathrm{C}$ to $33.18{ }^{\circ} \mathrm{C}$. In comparison to Compact types, LCZs with open and sparse type were found cooler. LCZ $6 \mathrm{~B}$ (scattered trees nested in open low-rise) records the lowest temperature of $8.52^{\circ} \mathrm{C}$ on $27^{\text {th }} \mathrm{Dec}$ at 6:50 am. LCZ 6 ranks second in lowest minimum temperature of $10.69^{\circ} \mathrm{C} \mathrm{AT} \mathrm{7:10} \mathrm{am} \mathrm{on} \mathrm{the} \mathrm{same} \mathrm{day.} \mathrm{A} \mathrm{lower} \mathrm{rate}$ of cooling is observed in LCZ 3 . As a result, it's minimum temperature $\left(13.21-15.39{ }^{\circ} \mathrm{C}\right)$ is comparatively higher than the other regions. $\mathrm{LCZ}_{3_{2}}$ records the lowest maximum temperature $28.07^{\circ} \mathrm{C}$ whereas the highest maximum temperature range of $33.18{ }^{\circ} \mathrm{C}$ was recorded by $\mathrm{LCZ}_{3}$, followed by LCZ $9 \mathrm{DBA}$ and $\mathrm{LCZ}_{3 \mathrm{~F}}$ of DDN station. LCZ 3 and its subclasses show inconsistency in ranking for the highest range of maximum temperature.

RH during winter ranges from $15.9 \%-97.8 \%$. Maximum RH was found in LCZ $6_{\mathrm{B}}$. LCZ 3 and its subtypes show a lower range of maximum $\mathrm{RH}$. $\mathrm{LCZ}_{3}$ and $3_{\mathrm{F}}$ also recorded minimum $\mathrm{RH}$ during winter. The difference in maximum RH between the LCZs was found to be $22.1 \%$.

In summer, the temperature varies within the range of $19.50-47.06{ }^{\circ} \mathrm{C}$. LCZ $6_{\mathrm{B}}$ recorded the lowest temperature in summer whereas LCZ 9 recorded the highest temperature. Maxima and minima temperature ranges vary for $\mathrm{LCZ}_{3}$ and its subclasses. The maximum temperature reached by an LCZ ranged between $40.83-47.06^{\circ} \mathrm{C}$ whereas the minimum temperature reached was found between $19.50-25.7^{\circ} \mathrm{C}$. RH 


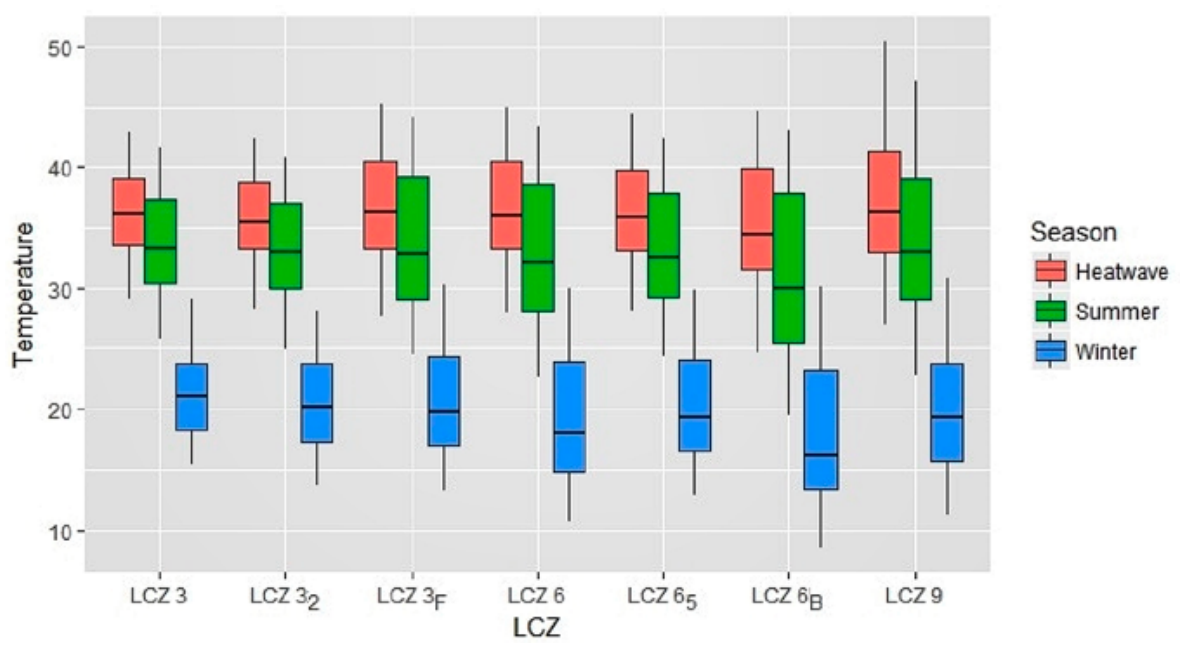

Figure 3. Temperature (in ${ }^{\circ} \mathrm{C}$ ) box plot of LCZs during winter, summer and heatwave period

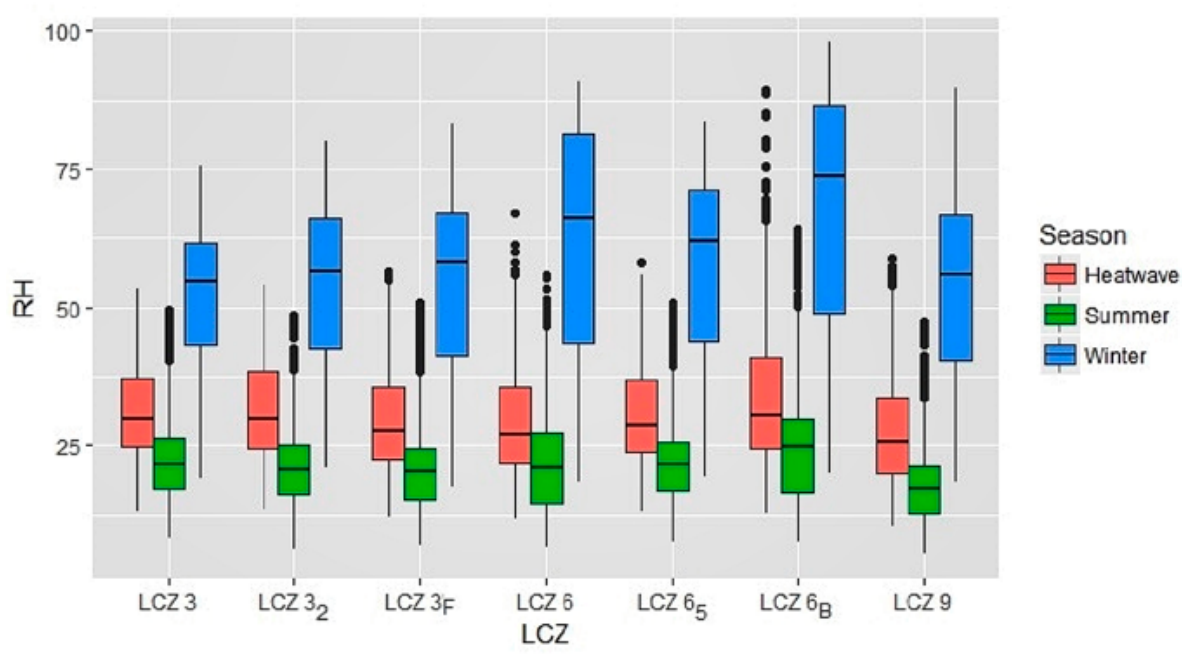

Figure 4. RH (in \%) box plot of LCZs during winter, summer and heatwave period

range lies between 5.4\% - 64.3\% in summer. Maximum $\mathrm{RH}$ was found in open type of LCZs $\left(\mathrm{LCZ} 6_{\mathrm{B}}\right.$ followed by LCZ 6).

\section{Thermal anomaly}

LCZ had a uniform and distinct thermal anomaly pattern (Figure 5) during the nocturnal as well as early morning period (6 am to 9 am). After 3 hours of sunrise, the thermal anomaly of all major local climate zones starts to converge towards the mean. LCZ's thermal anomaly tends to shift their polarity and move towards the extreme ends, which is different for each LCZ, during the working period. This is more evident during the winter season wherein thermal anomaly ranges from -3.27 to $2.33^{\circ} \mathrm{C}$. Compact and sparse type LCZs remains on the positive axis of the thermal anomaly, higher than the group mean temperature, for a longer duration as compared to open type LCZs.
Summer thermal anomaly plot ranges between -3.46 to $3.66^{\circ} \mathrm{C}$ and shows almost symmetric convergence and divergence trend along with the group average. LCZ 3 records minimum thermal anomaly during working hours while LCZ 9 records minimum thermal anomaly during nocturnal hours. LCZ 3 and its subtypes show a distinct thermal behavior during the working hours. $\mathrm{LCZ}_{3 \mathrm{~F}}$ is present on the positive extreme, while $\mathrm{LCZ}_{3}$ lies close to city average and $\mathrm{LCZ}_{3_{2}}$ remains on the negative extreme of the thermal anomaly.

During the heatwave period, thermal anomaly ranges from -2.66 to 4.54 . Except for LCZ 9 and LCZ $3_{2}$, all other LCZ lie within the range of -1 to +1 thermal anomaly for most of the time. Maximum thermal anomaly is recorded by LCZ 9 during this period. LCZ 6 ranks second in the highest thermal anomaly. This is due to a smaller range of high temperature exhibited by all LCZs (Figure 3). There is no clear ther- 
mal anomaly trend during heatwaves for the major part of the day. Only during the nocturnal hours, LCZ shows distinct thermal anomaly pattern.

\section{Comfort}

In the winter season, only during the working hours, all LCZs lie in the second zone of discomfort wherein $50 \%$ of the population is affected. RSI shows that all LCZs were comfortable most of the time, except during working hours between 12:30 - 17:20 time. During this period, LCZ showed comfort wherein less than $75 \%$ of the population were unstressed. The maximum exposure of this discomfort was found in LCZ 6 and LCZ $6_{\mathrm{B}}$. $\mathrm{LCZ}_{3_{2}}$ and $\mathrm{LCZ}_{3}$ were uncomfortable for the short interval of 60 minutes and 100 minutes respectively.

As per DI, almost everyone experiences discomfort during the summer. Discomfort is more profound during the working hours. During nocturnal hours and early morning period, only LCZ $6^{\mathrm{B}}$ lies in a no discomfort zone for five-hour duration whereas remaining LCZs lie in the second zone of discomfort during the same hours. Peak discomfort was noticed in LCZ 9 as everyone feels heat stress during 14:10-17:00 interval of working hours (see Figure 5). Comparatively, $\mathrm{LCZ}_{3_{2}}$ experiences short exposure (12:30-16:50 hours) of the zone with 'more than 50\% population feeling discomfort'. RSI exhibit a similar trend of discomfort during the summer. LCZ 9 shows the poorest comfort levels as it crosses the zone IV where $75 \%$ population feels distressed during 14:10-17:10 working hours. LCZ $3_{\mathrm{F}}$ has a maximum exposure of discomfort zone III (an upper limit of comfort) whereas LCZ ${ }_{3}$ remains in the same zone for a shorter time duration. This also indicates that LCZ subclasses play an important role in determining comfort levels. RSI of LCZ $6_{B}$ during the nocturnal and early morning period (3:00 am 7:40 am) that lies in the highest comfort level. LCZ 6, LCZ 9 and LCZ D also attain the highest comfort during the early morning periods for a few hours.

The discomfort index during heat wave period (as shown in Figure 5) shows a longer duration of discomfort during working hours and early transitional period (morning 10:30 to 18:30). During this period DI lies within Zone IV of comfort condition representing the complete population feeling heat stress. LCZ 9 is a major concern in terms of comfort as it touches the zone of emergency at 15:40 hours. As per RSI study, except LCZ $3_{2}$ all the LCZs remain highly uncomfortable i.e. more than $75 \%$ population feels distressed. The conditions during the heat wave can be fatal since no comfort is observed throughout the day in any of the LCZs. LCZ 9 is the most severe case of discomfort as it enters into the $100 \%$ distressed zone for a few moments.

Irrespective of the time periods selected, the thermal anomaly was significantly different for each LCZ
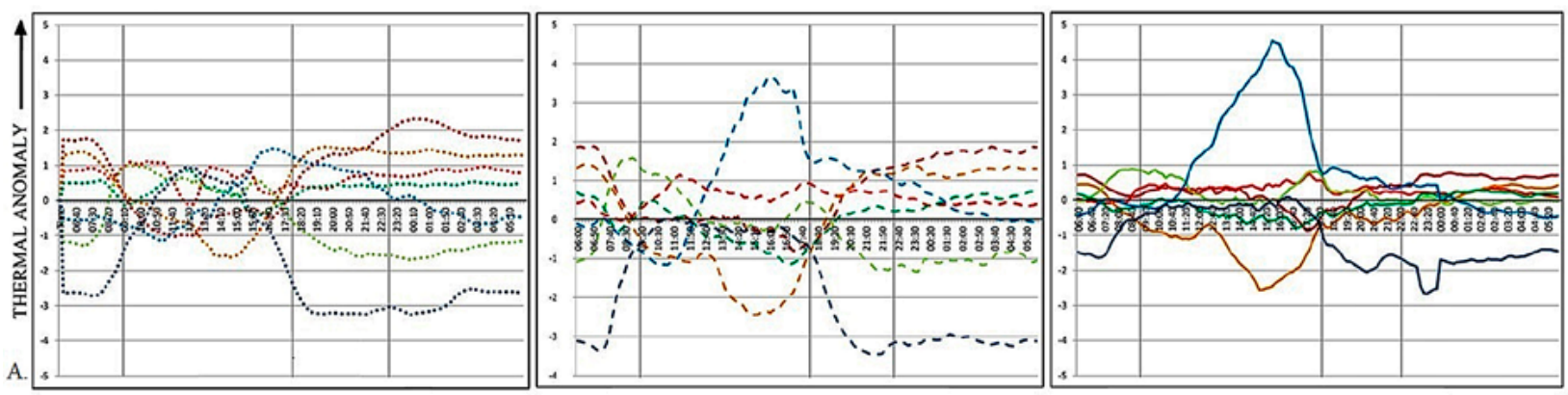

$-\mathrm{LCZ}_{3}-\mathrm{LCZ}_{3_{\mathrm{F}}}-\mathrm{LCZ}_{3}-\mathrm{LCZ}_{6}$

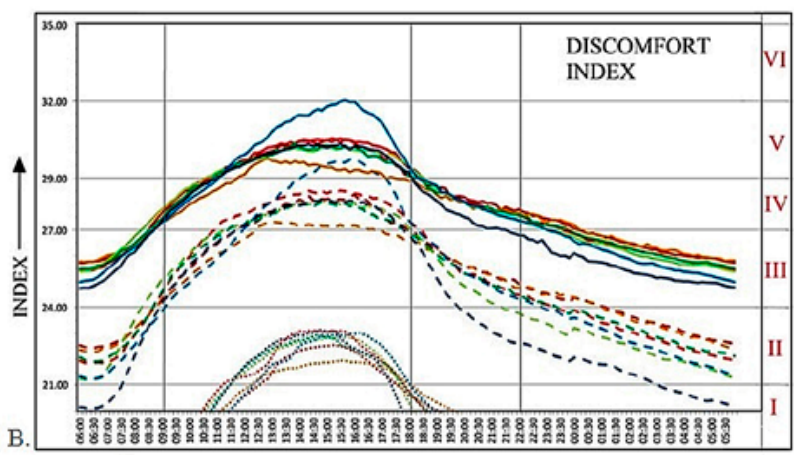
TIME

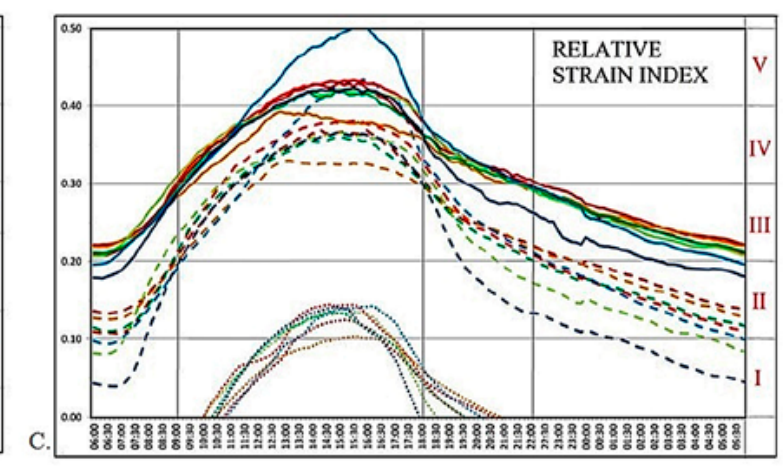

........ WINTER

Figure 5. LCZ trend for 10 days of hourly mean TA (a), DI (b), and RSI (c) observed during different season starting from 6:00 hrs and intervals at 9:00 hrs, 18:00 hrs and 22:00 hrs (IST) indicating early morning, working hours, transitional hours and nocturnal time period respectively 
Table 5. ANOVA using Welch's method for mean discomfort index, relative strain index and thermal anomaly

\begin{tabular}{|c|c|c|c|c|}
\hline \multirow[t]{2}{*}{ Month } & \multirow[t]{2}{*}{ Period } & \multicolumn{3}{|c|}{ Null Hypothesis (H0): All LCZs have Similar Mean Group } \\
\hline & & DI & RSI & TA \\
\hline \multirow[t]{4}{*}{ Winter } & Complete Day & $*$ & * & $*$ \\
\hline & Working Hours & All same & All same & * \\
\hline & Transitional Hours & $*$ & * & $*$ \\
\hline & Nocturnal Hours & $*$ & * & * \\
\hline \multirow[t]{4}{*}{ Summer } & Complete Day & All LCZs are same except LCZ 6 \& 9 & * & $*$ \\
\hline & Working Hours & * & All LCZs are same except LCZ $\sigma_{5}$ and $\sigma_{B}$ & $*$ \\
\hline & Transitional Hours & $*$ & * & $*$ \\
\hline & Nocturnal Hours & $*$ & * & $*$ \\
\hline \multirow[t]{4}{*}{ Heat-wave } & Complete Day & All same & All LCZs are same except $6_{B}$ and 9 & $*$ \\
\hline & Working Hours & $*$ & * & $*$ \\
\hline & Transitional Hours & All LCZs are same except LCZ 6B and 3 & * & $*$ \\
\hline & Nocturnal Hours & $*$ & $*$ & $*$ \\
\hline
\end{tabular}

* Group mean of the index is significantly different for each LCZ at the selected time period ( $p$ value $<0.05$ )

(see Table 5). Both the comfort indices establish that evening (transition period) and nocturnal hours are significantly different for all the LCZs during winter, summer, and heatwaves. However, similar outdoor thermal comfort was found during working hours in winter season wherein LCZs were found to have an overlapping mean of thermal comfort indices. During an average heat wave day, RSI shows the significant comfort difference between LCZs $(\mathrm{p}=0.03)$ whereas TDI result state the opposite $(\mathrm{p}=0.142)$. This suggests LCZs' response to TDI is more sensitive as compared to RSI.

\section{Discussion}

The variation in outdoor thermal comfort amongst different LCZs indicates the importance of spatial land-cover features such as vegetation cover (Takács et al. 2016), urban canopy, surface cover, and anthropogenic factors. Built density or compactness affect the shading conditions and amount of solar radiation received in an LCZ. It was observed that area with a higher aspect ratio, such as LCZ 3 in this study, observe building effect resulting in a lower range of discomfort during afternoon working hours. Similarly, LCZ 9 with the lowest range of aspect ratio show comparative highest outdoor thermal discomfort. This corroborates with the findings of comfort studies conducted in other studies using LCZ. Müller et al (2014) observed compared LCZ's outdoor thermal comfort in Oberhausen (Germany) using PET index and found similar observation. Balogun et al (2010) conclude $\mathrm{LCZ}_{9}$ is more uncomfortable during the day than LCZ 3 using Thermohygrometric Index (THI or DI). Vegetation and the urban setting were also observed as a factor affecting comfort. LCZs with high pervious surface cover and a minimum ratio of vegetation, such as LCZ 9, shows higher exposure to discomfort during the day and an opposite trend of comfort during the night. For LCZ $6_{\mathrm{B}}$, greater vegetation cover and location at inner city regions contribute to the negative thermal anomaly and lower discomfort ranges for a major period of time.

The result from ANOVA test also indicates the importance of time period segregation for assessing comfort. During working hours of summer and heatwave, LCZs show distinct comfort pattern differentiation. The significant difference $(p<0.05)$ in mean thermal anomaly and mean thermal discomfort during these hours substantiates the recent findings on heatwave risk's non-uniformity in complex urban areas (Geletič et al., 2018; Savić, et al., 2018; Lehnert et al. 2018). Temporal assessment of comfort assists in the identification of critical time period having maximum exposure to discomfort. Each LCZ observed varying diurnal range and leading to distinct thermal anomaly profile. During nocturnal hours, depending on the compactness, surface and material properties, each LCZ was observed to have a different rate of cooling. As a result, variation in thermal anomaly begins to rise away from the group mean of LCZ temperature, indicating higher UHI effect. Few hours after sunrise, the urban areas start to gain more solar radiation and the thermal anomaly begins to converges closer to the mean. This supports the preference of selecting nocturnal hours to explore LCZ's maximum UHI magnitude. While winters lie in comfort zones 
for a major time period, extreme discomfort is observed throughout the summer and heatwave period irrespective of the hours of the day. Working hours were observed as a critical period, specifically during the afternoon, as LCZs are exposed to severe discomfort in summer and heatwave. Working hours reaches an alarming state during heatwaves as all LCZs approach toward the zones of medical emergency or heat stroke (DI>32 and RSI=0.5). Transitional period ranks second in terms of the critical period of comfort. This period witnessed several changes in meteorological and anthropogenic variation. Post sunset, while some areas begin to radiate heat, the thermal capacity of building surfaces in different LCZ affect the cooling rate. Traffic conditions escalate during the same hour. Except for LCZ $6_{\mathrm{B}}$, comfort ranges of all LCZs lie very close to each other during this period.

\section{Conclusion}

This study is oriented for urban planners and policymakers to incorporate an understanding of urban form and comfort in spatial planning. Local climate zone classification provides a scientific framework to understand the synergy between the built environment and urban climate. This study contributes to the understanding of local climate zones and its potential to evaluate outdoor thermal comfort. Through spatial and temporal investigation of comfort in different LCZs, the study guides through the 'when' and 'where' part of mitigation. The study helps in identifying outdoor comfort critical local climate zones and time period of maximum exposure. LCZ classification could thus be incorporated in the preparation of heat action plan (HAP) as an effective strategy for management and adaptation. Use of two simple outdoor thermal comfort indices and corroboration of results with other studies with different indices show that the methodology adopted in this study can be replicated using different cities and different indices. However, limitation of this study lies in considering very few meteorological variables and not considering essential comfort parameters such as solar radiation, wind speed, and clothing conditions. This study could be strengthened further with the incorporation of these variables.

The study guides in comfort assessment using minimum resources without any extrapolation of comfort parameters. It presents a strong groundwork for evaluating comfort and LCZ in the tropics. Advance research alternatives with various statistical and simulation tools could be adopted for further evaluating the identified critical regions. Urban development policies leading to the development for critical LCZs could be scrutinized and revised for optimizing outdoor thermal comfort conditions. The future scope of work includes the assessment of LCZ composition for prioritizing comfort affecting parameters.

\section{Acknowledgement}

The study is supported and funded by the Department of Science and Technology, and is funded by Science and Engineering Research Board [DST-SERB project SB/S4/AS-110/2013].

\section{References}

Abdel-Ghany, A.M., Al-Helal, I.M., \& Shady, M.R. (2013). Human Thermal Comfort and Heat Stress in an Outdoor Urban Arid Environment: A Case Study. Advances in Meteorology, 1-7. doi:10.1155/2013/693541

Arsenović, D., Lehnert, M., Fiedor, D., Šimáček, P., Středová, H., Středa, T., \& Savić, S. (2019). Heatwaves and Mortality in Czech Cities: A Case Study for the Summers of 2015 and 2016. Geographica Pannonica, 23(3), 162-172.

ASHRAE (2013). Standard-55 Thermal Environmental Conditions for Human Occupancy.

Bajšanski, I. V., Milošević, D. D., \& Savić, S. M. (2015). Evaluation and improvement of outdoor thermal comfort in urban areas on extreme temperature days: Applications of automatic algorithms. Building and Environment, 94, 632-643. doi:10.1016/j. buildenv.2015.10.019

Balogun, A.A., Balogun, I.A., \& Adeyewa, Z.D. (2010). Comparisons of urban and rural heat stress conditions in a hot-humid tropical city. Global Health Action, 3(1), doi:10.3402/gha.v3io.5614

Bechtel, B., Alexander, P., Böhner, J., Ching, J., Conrad, O., Feddema, J., Mills, G., See, L., \& Stewart, I. (2015). Mapping local climate zones for a worldwide database of the form and function of cities. ISPRS 
International Journal of Geo-Information, 4(1), 199219. doi:10.3390/ijgi 4010199

Budd, G.M. (2001). Assessment of thermal stress-the essentials. Journal of Thermal Biology, 26(4-5), 371374. doi:10.1016/so306-4565(01)ooo46-8

CRISIL (2015). City Development Plan for Nagpur City - 2041. Ministry of Urban development; Risk and Infrastructure Solutions Limited (CRISIL).

Emmanuel, R. (2005). Thermal comfort implications of urbanization in a warm-humid city: the Colombo Metropolitan Region (CMR), Sri Lanka. Building and Environment, 40(12), 1591-1601. doi:10.1016/j. buildenv.2004.12.004

Fanger, P.O. (1970). Thermal comfort: Analysis and applications in environmental engineering. Danish Technical Press.

Fischereit, J., \& Schlünzen, K.H. (2018). Evaluation of thermal indices for their applicability in obstacleresolving meteorology models. International journal of biometeorology, 62(10), 1887-1900. doi:10.1007/ soo484-018-1591-6

de Freitas, C.R., \& Grigorieva, E.A. (2017). A comparison and appraisal of a comprehensive range of human thermal climate indices. International Journal of Biometeorology, 61(3), 487-512. doi:10.1007/ soo484-016-1228-6.

Geletič, J., Lehnert, M., Savić, S., \& Milošević, D. (2018). Modelled spatiotemporal variability of outdoor thermal comfort in local climate zones of the city of Brno, Czech Republic. Science of the Total Environment, 624, 385-395. doi:10.1016/j.scitotenv.2017.12.076

Hanna, E.G., Kjellstrom, T., Bennett, C., \& Dear, K. (2011). Climate Change and Rising Heat: Population Health Implications for Working People in Australia. Asia Pacific Journal of Public Health, 23, 14S-26S. doi:10.1177/1010539510391457

National Disaster Management Authority (2018). Heat Wave. http://www.ndma.gov.in/en/media-public-awareness/disaster/natural-disaster/heat-wave. html. (Accessed 29.08.2018)

Johansson, E., Thorsson, S., Emmanuel, R., \& Krüger, E. (2014). Instruments and methods in outdoor thermal comfort studies-The need for standardization. Urban climate, 10, 346-366

Kotharkar, R., Bahadure P., \& Sarda N. (2014). Measuring Compact Urban Form: A Case of Nagpur City, India. Sustainability, 6(7), 4246-4272. doi:10.339o/ su6074246

Kotharkar, R., \& Bagade, A. (2018). Local Climate Zone classification for Indian cities: A case study of Nagpur. Urban Climate, 24, 369-392. doi:10.1016/j. uclim.2017.03.003.

Kyle, W.J. (1992). Summer and winter patterns of human thermal stress in Hong Kong. In Proceedings of the 2nd Int. Conference on East Asia and Western Pacific Meteorology and Climate, Hong Kong, Kyle WJ, Chang CP (Eds.) (pp. 557-83).

Lehnert, M., Kubeček, J., Geletič, J., Jurek, M., \& Frajer, J. (2018). Identifying hot and cool spots in the city centre based on bicycle measurements: the case of Olomouc, Czech Republic. Geographica Pannonica, 22(4), 230-240.

Müller, N., Kuttler, W., \& Barlag, A.B. (2014). Counteracting urban climate change: adaptation measures and their effect on thermal comfort. Theoretical and applied climatology, 115(1-2), 243-257. doi:10.1007/s00704-013-0890-4

Nagano, K., \& Horikoshi, T. (2011). New index indicating the universal and separate effects on human comfort under outdoor and non-uniform thermal conditions. Energy and Buildings, 43(7), 1694-1701. doi:10.1016/j.enbuild.2011.03.012

Lemonsu, A., Viguié, V., Daniel, M., \& Masson, V. (2015). Vulnerability to heat waves: Impact of urban expansion scenarios on urban heat island and heat stress in Paris (France). Urban Climate,14, 586-605. doi:10.1016/j.uclim.2015.10.007

Milošević, D. D., Savić, S. M., Marković, V., Arsenović, D., \& Šećerov, I. (2016). Outdoor human thermal comfort in local climate zones of Novi Sad (Serbia) during heat wave period. Hungarian Geographical Bulletin, 65(2), 129-137. doi:10.15201/hungeobull.65.2.4

Milošević, D., Bajšanski, I., \& Savić, S. (2017). Influence of changing trees locations on thermal comfort on street parking lot and footways. Urban Forestry and Urban Greening, 23, 113-124. doi:10.1016/j. ufug.2017.03.011

National Disaster Management Authority (2016). Guidelines for Preparation of Action Plan - Prevention and Management of Heat-Wave. Government of India. https://ndma.gov.in/images/guidelines/ guidelines-heat-wave.pdf. (Accessed 22.08.2018.)

Neuberger, H., \& Cahir, J. (1969). Principles of climatology: a manual in earth science. New York: Holt, Rinehart and Winston.

Nieuwolt, S. (1977). Tropical climatology. An introduction to the climates of the low latitudes. John Wiley and Sons.

Müller, N., Kuttler, W., \& Barlag, A.B. (2014). Counteracting urban climate change: adaptation measures and their effect on thermal comfort. Theoretical and applied climatology, 115(1-2), 243-257.

Oke, T.R. (1982). The energetic basis of the urban heat island. Quarterly Journal of the Royal Meteorological Society, 108, 1-24. doi:10.1002/qj.49710845502

Polydoros. A., \& Cartalis, C. (2014). Assessing thermal risk in urban areas - an application for the urban agglomeration of Athens. Advances in Build- 
ing Energy Research, 8, 74-83. doi:10.1080/17512549. 2014.890536

Rose, A.L., Horrison, E., \& Venkatachalam, L.J. (2011). Influence of built form on the thermal comfort of outdoor urban spaces. In The 5th International Conference of the International Forum of Urbanism (IFoU). Singapore: Department of Architecture, National University of Singapore.

Savić, S., Marković, V., Šećerov, I., Pavić, D., Arsenović, D., Milošević, D., Dolinaj, D., Nagy, I., \& Pantelić, M. (2018). Heat wave risk assessment and mapping in urban areas: case study for a midsized Central European city, Novi Sad (Serbia). Natural hazards, 91(3), 891-911. doi:10.1007/s11069-017-3160-4

Souch, C.A., \& Souch, C. (1993). The effect of trees on summertime below canopy urban climates: a case study Bloomington, Indiana. Journal of Arboriculture, 19(5), 303-312.

Stathopoulou, M., Cartalis, C., \& Andritsos, A. (2005). Assessing the thermal environment of major cities in Greece. In 1st International Conference on Passive and Low Energy Cooling for the Built Environment, Santorini, Greece May 2005.

Stewart, I.D., \& Oke, T.R. (2012). Local Climate Zones for Urban Temperature Studies. Bulletin of the American Meteorological Society, 93(12), 1879-1900. doi:10.1175/bams-d-11-00019.1

Takács, Á., Kiss, M., Gulyás, Á., Tanács, E., \& Kántor, N. (2016). Solar permeability of different tree species in Szeged, Hungary. Geographica Pannonica, 2o(1), 32-41.

Thom, E.C. (1959). The Discomfort Index. Weatherwise, 12(2), 57-61. doi:10.1080/00431672.1959.992696o.

Unger, J. (1999). Comparisons of urban and rural bioclimatological conditions in the case of a CentralEuropean city. International Journal of Biometeorology, 43(3), 139-144. doi:10.1007/soo4840050129

Unger, J., Skarbit, N., \& Gál, T. (2018). Evaluation of outdoor human thermal sensation of local climate zones based on long-term database. International Journal of Biometeorology, 62(2), 183-193. doi:10.1007/ soo484-017-1440-Z

Verdonck, M.L., Demuzere, M., Hooyberghs, H., Beck, C., Cyrys, J., Schneider, A., Dewulf, R., \& Van Coillie, F. (2018). The potential of local climate zones maps as a heat stress assessment tool, supported by simulated air temperature data. Landscape and Urban Planning, 178, 183-197. doi:10.1016/j.landurbplan.2018.06.004

Villadiego, K., \& Velay-Dabat, M.A. (2014). Outdoor thermal comfort in a hot and humid climate of Colombia: A field study in Barranquilla. Building and Environment, 75, 142-152, doi:10.1016/j.buildenv.2014.01.017

Wu, Z., Kong, F., Wang, Y., Sun, R., \& Chen, L. (2016). The impact of greenspace on thermal comfort in a residential quarter of Beijing, China. International journal of environmental research and public health, 13(12), doi:10.339o/ijerph13121217 